\title{
Revisões Atuais para Todos
}

om esta edição extra da Revista Brasileira de Reumatologia (RBR), visamos oferecer aos nossos leitores a oportunidade de acessarem, sem grande demora, nove bem cuidadas, completas e atuais revisões sobre temas importantes da reumatologia. Nossa intenção foi a de não deixar acumular os artigos de revisão que, com o passar do tempo, deixariam de ter $\mathrm{o}$ aspecto de atualidade. Essa preocupação decorreu da observação do evidente salto quantitativo (e qualitativo) de manuscritos submetidos à nossa revista. Os números são claros. Enquanto, em 2004, foram submetidos 15 artigos originais, 16 artigos de revisão e 12 relatos de casos, em 2005, foram submetidos 33 artigos originais, 24 artigos de revisão e 26 relatos de casos. Para cumprirmos as exigências do SciELO, mantemos um fluxo de publicações prioritário para artigos originais e relatos de casos e com isso, se não tivéssemos esse suplemento extra, uma série de artigos de revisão se acumulariam.

Contamos aqui com duas revisões sobre vasculites primárias, que apesar de serem raras são assunto obrigatório na medicina de hoje $\mathrm{e}^{(1,2)}$; um artigo sobre

\section{REFERÊNCIAS}

1. Souza AWS, Neves RMS, Oliveira KR, Sato EI. Tratamento da Arterite de Takayasu. Rev Bras Reumatol 46, Supl 1: 2-7, 2006.

2. Neves FS, Moraes JCB, Gonçalves CR. Síndrome de Behçet: à Procura de Evidências. Rev Bras Reumatol 46, Supl 1: 21-29, 2006.

3. Riera R, Abre MM, Ciconelli RM. Revisões Sistemáticas e Metanálises na Reumatologia. Rev Bras Reumatol 46, Supl 1: 8-11, 2006.

4. Freire EAM, Nepomuceno JCA, Maia IO, Ciconelli RM. Doenças Reumáticas e Infertilidade Masculina. Rev Bras Reumatol 46, Supl 1: 12-20, 2006.

5. Pereira HLA, Ribeiro SLE, Ciconelli RM, Fernandes ARC. revisões sistemáticas e metanálises, que nos ajuda a entender melhor a literatura especializada ${ }^{(3)}$; uma revisão sobre a infertilidade masculina em pacientes com doenças reumatológicas, que ressalta questões de grande interesse prático ${ }^{(4)}$; duas interessantes abordagens sobre doenças infecciosas freqüentes em nosso meio que podem se apresentar com manifestações musculoesqueléticas a saber, hanseníase e $\operatorname{AIDS}^{(5,6)}$; duas revisões sobre espondiloartropatias soronegativas, uma sobre as manifestações osteoarticulares das doenças inflamatórias intestinais e outra sobre instrumentos de avaliação da espondilite anquilosante ${ }^{(7,8)}$. E, encerrando esse suplemento, temos uma revisão sobre as manifestações cardiovasculares da artrite reumatóide, um tema da ordem do dia ${ }^{(9)}$.

Com o objetivo de sempre oferecer algo mais ao nosso leitor, publicamos essa edição e desejamos a todos uma boa leitura.

Lais V. Lage e Roger A. Levy Editores Científicos da RBR
Avaliação por Imagem do Comprometimento Osteoarticular e de Nervos Periféricos na Hanseníase. Rev Bras Reumatol 46, Supl 1, 30-35: 2006.

6. Borjaille BP, Brandão LR, Hasegawa TM, Rosa RF, Antonio SF, Chahade WH. Osteonecrose e Síndrome da Imunodeficiência Adquirida. Rev Bras Reumatol 46, Supl 1: 36-44, 2006.

7. Lanna CCD, Ferrari MLA, Carvalho MAP, Cunha AS. Manifestações Articulares em Pacientes com Doença de Crohn e Retocolite Ulcerativa. Rev Bras Reumatol 46, Supl 1: 45-51, 2006.

8. Torres TM, Ciconelli RM. Instrumentos de Avaliação em Espondilite Anquilosante. Rev Bras Reumatol 46, Supl 1: 52-59, 2006.

9. Torigoe DY, Laurindo IMM. Artrite Reumatóide e Doenças Cardiovasculares. Rev Bras Reumatol 46, Supl 1: 60-66, 2006. 